\title{
Concrete Quality In Existing Reinforced Concrete Structures In The First Seismic Zone In Turkey
}

\author{
Ozer Sevim \\ Civil Engineering Department, Kirikkale University, Kirikkale, 71451 Turkey. \\ Phone: +90 (318) 357-4242; Fax: +90 (318) 357-2459, ozersevim@ @ku.edu.tr
}

\begin{abstract}
Turkey has faced many severe earthquakes and many buildings were damaged or collapsed. One of the most important reasons of this destruction is the low quality of concrete used in the structures. In order to improve the quality of concrete, the quality supervision of concrete is significant matter for accomplishing safety in reinforced concrete structures. For this purpose, test results of standard cube samples $(150 \times 150 \times 150 \mathrm{~mm})$ are collected from all cities located in first seismic zone in Turkey. The concrete quality is investigated in terms of years and concrete classes on the basis of two statistical parameters, mean and coefficient of variation of compressive strength of cube samples. The present study indicates that higher concrete classes have been used over the years. Besides, the mean concrete compressive strength is increased on the average of \% 60 . Results point out that higher concrete class is used in comparison with the years before the major earthquakes August 17th Kocaeli and the November 12th Düzce earthquakes in 1999.
\end{abstract}

Index Terms-Concrete quality, Concrete compressive strength, Concrete class, Coefficient of variation

\section{GENERAL INTRODUCTION}

$\mathrm{T}$ urkey is located in one of the most active earthquake regions in the World and has faced many severe earthquakes. After these earthquakes many buildings were damaged seriously or collapsed. One of the most important reasons of this destruction is low concrete quality.

In the most of the building sites, it is usually observed that the circumstances required for good quality concrete were not taken into consideration in an efficient manner until the last two decades and the concern of production of good quality concrete was not given notable importance in Turkey. Particularly before the two major earthquakes, namely the August 17th Kocaeli and the November 12th Düzce earthquakes in 1999 poor quality of concrete was commonly detected.

Concrete is a composite construction material prepared mainly with aggregate, cement and water. The wide variety of mix proportions possible allows it to be customized for a wide range of applications such as buildings, dams, reservoirs, pipes, foundations, motorways, roads, runways, brick/block walls, pavements, bridges, overpasses, parking structures, fences and poles and even boats. In this concept, concrete is the most used man-made product in the World. For this reason, this structural material is one of the most important subjects of researches conducted by civil engineers with respect to quality management. Especially, after the concrete is produced in ready-mixed concrete plant, the quality management came forward as one of the most important parameter in the stage of concrete production.

The aim of this study is to shed some light upon the quality of concrete production in first seismic zone in Turkey. In other words, whether or not the increase of the concrete quality observed in the earthquake regions after devastating earthquakes occurred in Turkey is investigated. The evaluation of concrete compressive strength is generally preferred to specify the concrete quality [1]. Therefore, the compressive strength results of the standard cube samples are collected and evaluated for the whole provinces located in first seismic zone in Turkey. Accordingly, on the basis of two statistical parameters, mean and coefficient of variation of compressive strength of cube samples, the concrete quality is assessed in terms of years and concrete classes.

\section{CONCRETE COMPRESSIVE STRENGTH}

The compressive strength of concrete can be defined as the maximum strength under the axial compression load. In order to quantify the compressive strength of concrete, different testing methods can be employed but the most popular and the most widely used methods is the standard test method. The major reason to realize this fact is that this kind of test is simple and relatively inexpensive. In addition, the determination of compressive strength provides information about the other features of concrete, e.g. the high compressive strength indicates the less water permeability and high durability. In order to find the compressive strength of the concrete, the standard-size samples prepared by fresh concrete are tested after curing time and curing procedure recommended by related standards and instructions. In this context, the aims of the determination of concrete compressive strength with standard test method are listed as follows: 
- In the design of structures, a specific value of the compressive strength of concrete is supposed and the computations are carried out according to this compressive strength value. The value determined by standard test method is taken into consideration in the structural design.

- Different factors which affect concrete properties such as the production method, sizes of samples, curing methods of samples is examined by standard test method.

- The value of compressive strength intended mix designs is the concrete compressive strength which will be defined by standard test method.

- The acceptance or rejection of the concrete in worksite is mainly dependent on standard test method.

In the standard test method, cylinder or cube-shaped samples are used. Both cube-shaped and cylinder-shaped samples are used in some countries such as Denmark, Sweden, Norway, and Turkey, while only cylinder-shaped samples are used in some countries such as New Zealand, Australia, France, Canada and the United States [2]. Diameter and length of standard-sized concrete cylinder sample are $150 \mathrm{~mm}$ and $300 \mathrm{~mm}$ respectively in concrete standards of many countries such as Turkey. On the other hand, the cube-shaped samples, the edges of which are $150 \mathrm{~mm}$, are extensively used. In testing press, the load speed applied these samples changes within a range of $0.2 \mathrm{MPa} / \mathrm{s}$ and $1.0 \mathrm{MPa} / \mathrm{s}$ (TS EN 123903)[3].

The compressive strength obtained by standard test method does not represent the actual compressive strength of concrete in structures. The concrete samples are tested under the uniformly disturbed axial load whereas the concrete in structure is not subjected to the effect of axial compressive load. In addition, the samples prepared for standard test methods are cured in much better conditions compared to the concrete in structures. Although the problems mentioned above are major sources of uncertainty on concrete compressive strength of concrete, there is a wide variety of factors that can affect actual compressive strength. These factors are summarized below:

- Quality of mixing water

- Water/Cement ratio

- Cement properties

- Surface property of aggregate

- Maximum size of aggregate

- Aggregate shape

- Amount of harmful substances in aggregate

- Properties and of mineral and chemical admixtures used in concrete

- Temperature and humidity in environment in which concrete is prepared, cured and poured.

- Age of samples

- Quantities of admixtures

- Preparing, transporting, placing and compaction procedures.
Typical stress-strain curves obtained from standard compressive tests of concrete are given in Figure 1. As presented in this figure, the concrete strength decreases with decreasing slope of curve. Lower strength means a larger strain capacity at failure; in other words, low-strength concrete is more ductile. The initial tangent to each curve, which can be called initial modulus of elasticity, increases with compressive strength of concrete increases. It is worth the mention here that the strain matching to maximum stress is approximately same for each curve and it is about 0.002 .

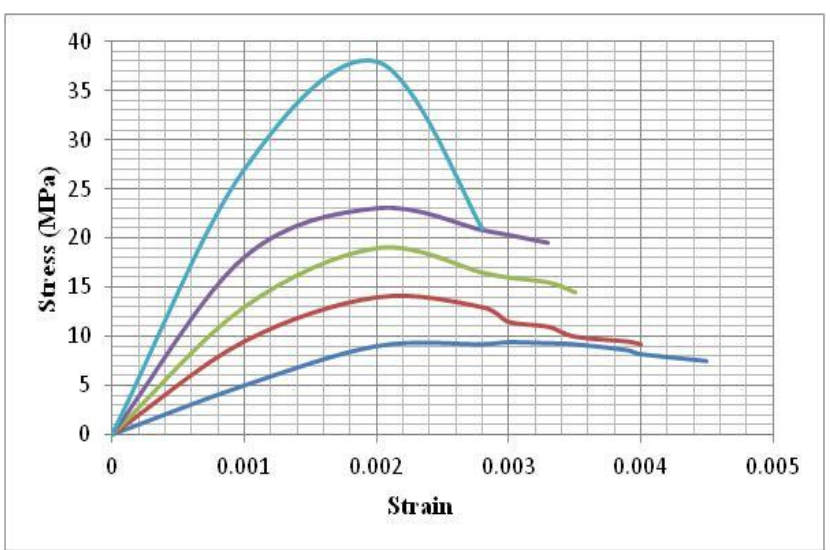

Fig 1. Stress-strain curves of concrete subjected to uniaxial compression [4]

\section{QUALITY CONTROL}

The main measure of the structural quality and classification of concrete is its compressive strength. Compressive strength of concretes is obtained by testing cylindrical samples of 300 $\mathrm{mm}$ height, $150 \mathrm{~mm}$ diameter, 28 days of age and cured under water throughout time. The compressive strength obtained from tests is known as the cylinder strength $\left(f_{c}\right)$. Strength of samples is variable quantity; hence, instead of using just one sample, three or more consecutive samples are grouped together. In TS500-2000, such a group of samples is considered to represent a unit concrete poured in the same day or on $450 \mathrm{~m}^{2}$ area which cannot exceed $100 \mathrm{~m}^{\mathrm{a}}$. The results of testing show a scatter or distribution of strength about mean strength. Test results are assumed to have a characteristic form called normal or Gaussian distribution. In order to calculate the required mean strength or simple mean strength $\left(f_{\text {mean }}\right)$, the following equations are used.

$f_{\text {mean }}=f_{\min }+s \sigma$

where $f_{\min }$ is minimum strength terms as the characteristic strength $\left(f_{c k}\right)$ in TS EN 206-2002 [5] and the specified design strength $\left(f_{c}\right)$ in ACI 318-08[6]. $\sigma$ is standard deviation which is calculated as;

$\sigma=\left(\frac{\Sigma\left(f_{i}-f_{m \varepsilon a n}\right)^{2}}{n-1}\right)^{1 / 2}$

where $n$ is number of test samples and $s$ is the probability 
factor, usually chosen between 1.64 and 2.33 for a probability that 1 in 20 or 1 in 100 , respectively, of strength value will fall below the minimum strength. If test results are clustered around the mean, it means that the samples are pretty tightly bunched together and the bell-shaped curve is steep. Such case the standard deviation is small. When the examples are spread apart and the bell curve is relatively flat. The second term, $s \sigma$, in Equation (1) is called margin[7]. The margin may be calculated based on results obtained using same plant, material and supervision. Most of the case, standards such as TS5002000 and EN206 recommended using a value $1 \mathrm{MPa}$ and $4 M P a$, respectively in the absence of necessary number of test results. For TS500-2000, the compressive strength of concrete fulfills the following conditions, it is said to conform the requirements[8];

$$
\begin{aligned}
& f_{\text {mean }}=f_{c k}+1(M P a) \\
& f_{\text {least }}=f_{c k}-3(M P a)
\end{aligned}
$$

It is possible to use cube samples instead of cylindrical samples. In such cases, size effect must be taken into considerations. Table 1 shows the relationship between the compressive strength of standard cube and standard cylindrical samples. The results of the samples does not fulfill the abovementioned conditions, the load carrying structure or the building elements, which have been obtained from the above conditions are re-evaluated according to the strength of concrete. If a significant reduction in strength, some measures must be taken.

TABLE I

CONCRETE CLASSES AND STRENGTHS

\begin{tabular}{cccc}
\hline \hline $\begin{array}{c}\text { Concrete } \\
\text { class }\end{array}$ & $\begin{array}{c}\text { Characteristic } \\
\text { compressive } \\
\text { strength, } \mathrm{f}_{\text {ck }} \\
(\mathrm{MPa})\end{array}$ & $\begin{array}{c}\text { Equivalent } \\
150 \text { mm cube } \\
\text { strength } \\
(\mathrm{MPa})\end{array}$ & $\begin{array}{c}\text { Modulus of } \\
\text { Elasticity } \\
(\mathrm{MPa})\end{array}$ \\
C16 & 16 & 20 & 27000 \\
C18 & 18 & 22 & 27500 \\
C20 & 20 & 25 & 28000 \\
C25 & 25 & 30 & 30000 \\
C30 & 30 & 37 & 32000 \\
C35 & 35 & 45 & 33000 \\
C40 & 40 & 50 & 34000 \\
C45 & 45 & 55 & 36000 \\
C50 & 50 & 60 & 37000 \\
\hline \hline
\end{tabular}

\section{STATISTICAL EVALUATION}

According to the research conducted in previous years, it have been identified that the quality of concrete produced in Turkey does not provide the desired parameters. For example, Akyuz and Uyan conducted a study on concrete quality of Istanbul and its surroundings[9]. They collected the test results of samples produced in various construction sites around Istanbul in 1986-1988. They claimed that even though in some construction areas where proper attention was assumed to be given for the production of concrete, $24 \%$ of concrete samples has a smaller value than minimum projected value (14 MPa). In addition, Firat stated that, in case the all concrete samples belonging to different concrete class was taken into account, the average compressive strength value is determined around 20.60 MPa for the years of 1990-1995[10].

In this study, the test results of standard cube samples which belongs the concrete produced in the most prone earthquake region of Turkey in the years of 2006, 2007, 2008, 2009, 2010, 2011, 2012 and 2013 are investigated statistically. The data used in this study are taken from The Ministry of Environment and Urban Planning, Head of the Department of Building Materials for some provinces of Turkey, Adiyaman, Aydin, Balikesir, Batman, Istanbul, Bingöl, Bolu, Burdur, Bursa, Canakkale, Çankırı, Denizli, Diyarbakır, Düzce, Erzincan, Isparta, Izmir, Kastamonu , Kırıkkale, Kırşehir, Kütahya, Manisa, Mugla, Mus, Samsun, Siirt, Tokat, Tunceli, Van, and Zonguldak. Turkey is divided into eighty one provinces. All provinces are separated into several different district. The provincial governorate is set in the central district. All provinces located in first seismic zone (I. degree zone) in Turkey are showed in the Figure 2.

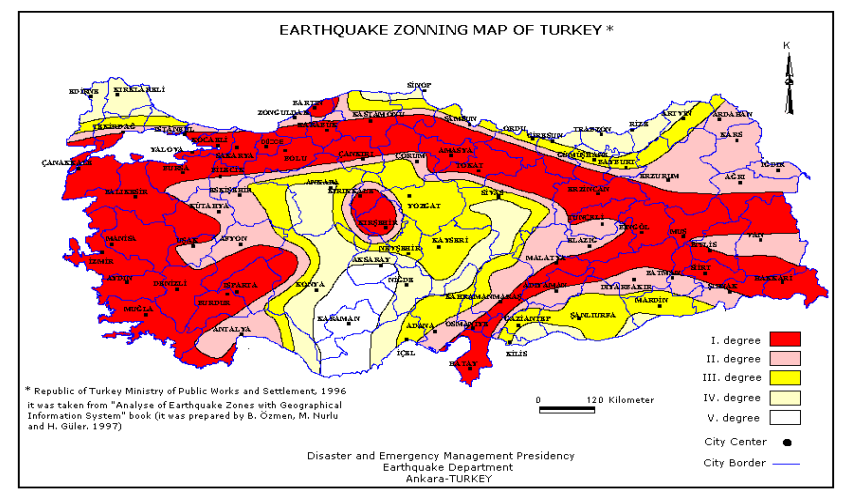

Fig 2. The provinces located different seismic zones in Turkey

In this study the statistical parameters of cube strength of concrete samples are examined according to years in order to determine the relative variability. Table 2 shows the averages of 28-day characteristic cube compressive strengths, standard deviations and coefficients of variation (cov) of concrete samples over the years. Cov is defined as the ratio of standart deviation to mean value. As can be seen from this table, 3639 concrete samples in 2013, 3099 concrete samples in 2012, 4710 concrete samples in 2011, 1785 samples in 2010, 810 samples in 2009, 426 samples between 2006 and 2008 and a total of 14469 samples were evaluated. Because the number of test results from the years of 2006 to 2008 is relative less than the number of samples then other years, year beetwen 2006 and 2008 are combined as only one year. Considering the all years, the weighted average compressive strength of concrete used in provinces located in the first seismic zone of Turkey is around $35 \mathrm{MPa}$ with the weighted average cov is around $0.21[11]$. 
TABLE II

THE STATISTICAL PARAMETERS OF 28-DAY CUBE COMPRESSIVE STRENGTH DATA OBTAINED FROM THE PROVINCES LOCATED IN THE FIRST SEISMIC ZONE OF TURKEY ACCORDING TO YEARS.

\begin{tabular}{ccccc} 
Years & $\begin{array}{c}\text { Number } \\
\text { of Data }\end{array}$ & $\begin{array}{c}\text { Compressiv } \\
\text { e Strength }\end{array}$ & $\begin{array}{c}\text { Standard } \\
\text { Deviation }\end{array}$ & $\begin{array}{c}\text { Coeffici } \\
\text { ent of } \\
\text { Variatio } \\
\text { n (COV) }\end{array}$ \\
$2006-2008$ & 426 & 32.06 & 7.41 & 0.23 \\
2009 & 810 & 34.64 & 7.42 & 0.21 \\
2010 & 1785 & 33.77 & 7.44 & 0.22 \\
2011 & 4710 & 35.08 & 7.45 & 0.21 \\
2012 & 3099 & 34.93 & 7.44 & 0.21 \\
2013 & 3639 & 39.93 & 7.42 & 0.18 \\
\hline
\end{tabular}

Concrete classes of all samples are showed in Table 3. In addition, the number of the samples and corresponding frequency in the considered concrete class are given in Table 3. The number of samples belonging to the concrete class of $\mathrm{C} 25$ is much greater than other concrete classes. The most of the concrete samples (about 97\%) are in the interval of C20C35. Concretes produced in the provinces located in first seismic zone of Turkey with a graphical representation are given in Figure 3.

TABLE III

THE FREQUENCIES OF 28-DAY CUBE COMPRESSIVE STRENGTHS FOR THE SOME INTERVALS BETWEEN 2006 AND 2012

\begin{tabular}{cccc}
\hline \hline Concrete & Number of & Frequency & Additive \\
Classes & Data & 0.0003 & 0.0003 \\
C12 & 3 & 0.0003 & 0.0006 \\
C14 & 3 & 0.0069 & 0.0075 \\
C16 & 75 & 0.0008 & 0.0083 \\
C18 & 9 & 0.2106 & 0.2189 \\
C20 & 2280 & 0.5082 & 0.7271 \\
C25 & 5502 & 0.2555 & 0.9825 \\
C30 & 2766 & 0.0161 & 0.9986 \\
C35 & 174 & 0.0011 & 0.9997 \\
C40 & 12 & 0.0003 & 1.0000 \\
C45 & 3 &
\end{tabular}

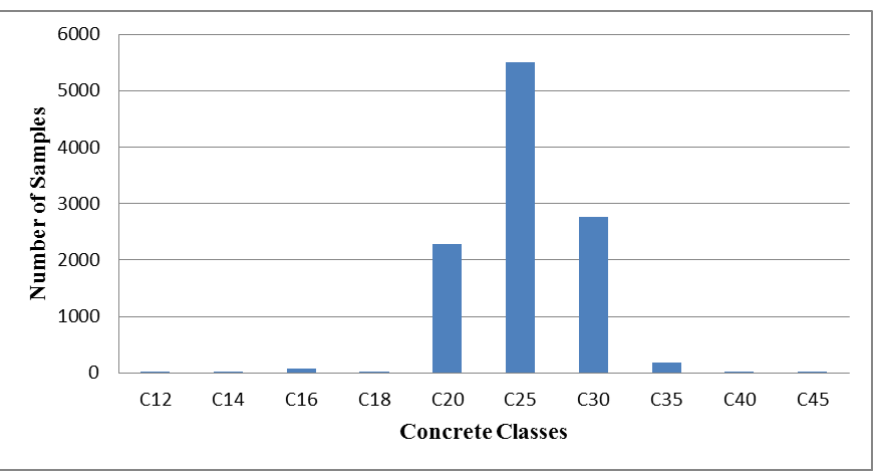

Fig 3. The distribution of the compressive strength of concrete produced in the provinces located in the first seismic zone of Turkey between 2006 and 2012
Although the general distribution of all concrete samples according to concrete class are seen in Table 3 and Figure 3, it is very important to know the distribution of the concrete samples belonging to only one concrete class. The concrete classes and its equivalent $150 \mathrm{~mm}$ cube strength $(\mathrm{MPa})$ are given in Table 1. In this study, the distribution of C20, C25 and $\mathrm{C} 30$ concrete cube strength of the samples obtained for the provinces located in first seismic zone of Turkey are presented in Figure 4, 5 and 6, respectively.

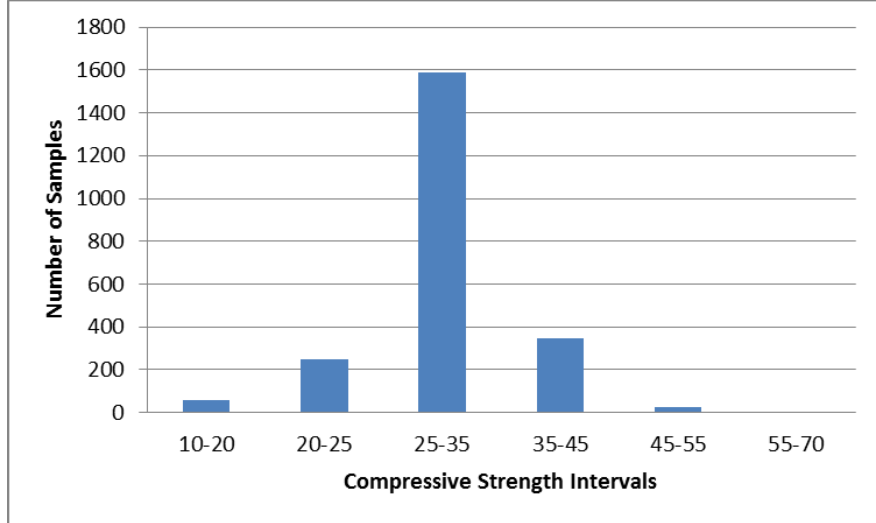

Fig 4. The number of samples belonging to some intervals of compressive strength (MPa) for C20 between 2006 and 2012

In Figure 4, the distribution of the test results of C20 concrete class is shown according to some compressive strength intervals. Considering a total of 2280 samples belonging to $\mathrm{C} 20$ concrete class, 327 samples have a value smaller than $25 \mathrm{MPa}$; in other words, $14 \%$ of samples do not provide the value of $25 \mathrm{MPa}$ prescribed in TS 500-2000[8].

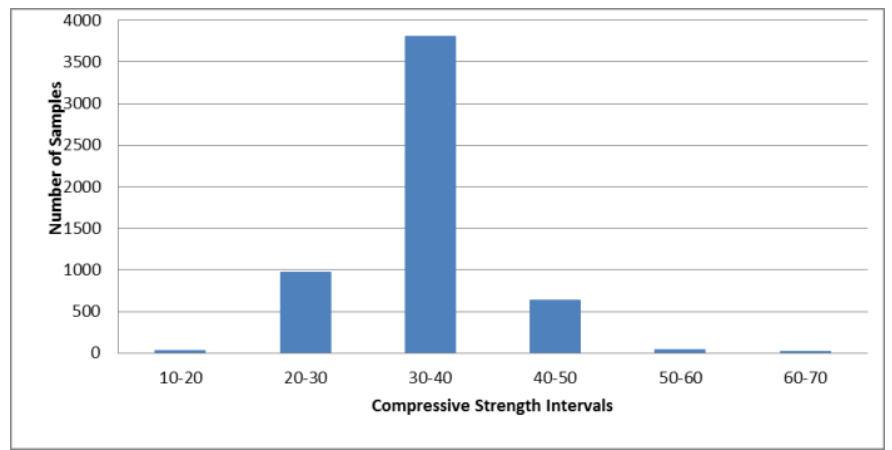

Fig 5. The number of samples belonging to some intervals of compressive strength (MPa) for C25 between 2006 and 2012

The distribution of the C25 samples produced in Turkey first degree earthquake zone is given in Figure 5. In this figure, the number of the samples of which compressive strength less than $30 \mathrm{MPa}$ is clearly seen. Regarding 5502 samples belonging to the class $\mathrm{C} 25$, a total of 1002 samples do not provide the required value $(30 \mathrm{MPa})$. That is, $18 \%$ of the samples are below the equivalent $150 \mathrm{~mm}$ cube compressive strength. 


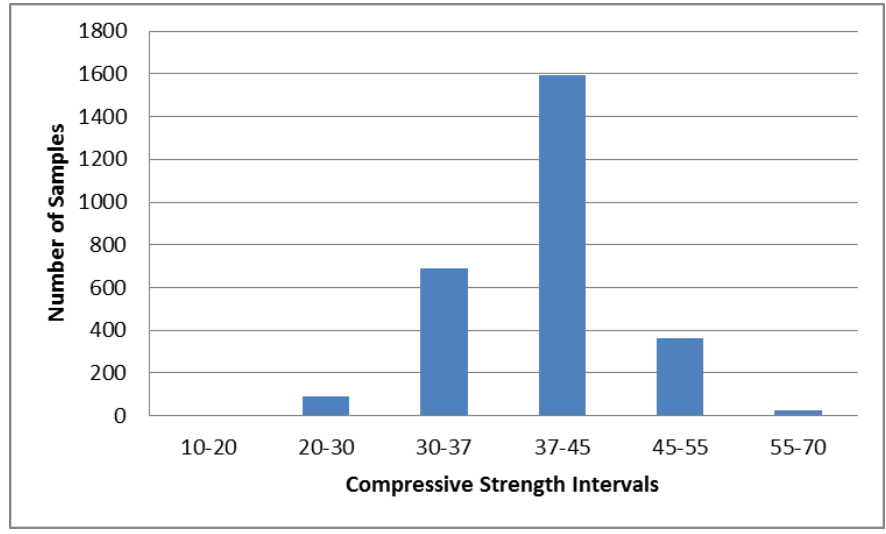

Figure 6. The number of samples belonging to some intervals of compressive strength (MPa) for C30 between 2006 and 2012

In Figure 6, the distribution of the test results of C30 concrete class is shown according to some compressive strength intervals. Figure 6 shows the certain number of the samples whose compressive strength is less than $37 \mathrm{MPa}$. Considering a total of 2766 samples belonging to C 30 concrete class, 783 samples have a value smaller than $37 \mathrm{MPa}$; in other words, $28 \%$ of samples do not provide the value of 37 MPa prescribed in TS 500-2000[8].

TABLE IV

THE FREQUENCIES OF 28-DAY CUBE COMPRESSIVE STRENGTHS FOR THE SOME INTERVALS IN 2013

\begin{tabular}{cccc}
\hline \hline Concrete & Number of & Frequency & Additive \\
Classes & Data & Frequency \\
C12 & 1 & 0.0008 & 0.0008 \\
C16 & 4 & 0.0033 & 0.0041 \\
C20 & 156 & 0.1286 & 0.1327 \\
C25 & 633 & 0.5218 & 0.6545 \\
C30 & 373 & 0.3075 & 0.9620 \\
C35 & 42 & 0.0346 & 0.9962 \\
C40 & 4 & 0.0033 & 1.0000 \\
\hline \hline
\end{tabular}

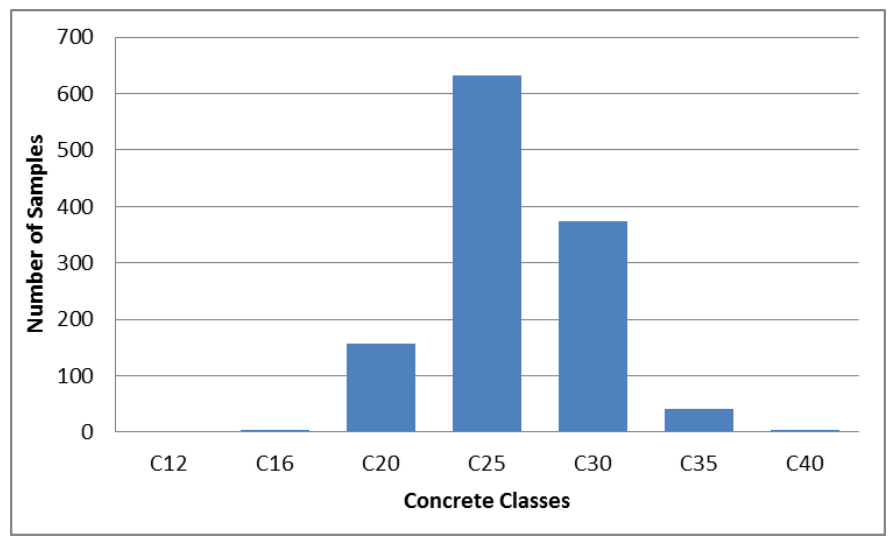

Fig 7. The distribution of the compressive strength of concrete produced in the provinces located in the first seismic zone of Turkey in 2013

Although the general distribution of all concrete samples according to concrete class in 2013 are seen in Table 4 and Figure 7, it is very important to know the distribution of the concrete samples belonging to only one concrete class. The distribution of C20, C25 and C30 concrete cube strength of the samples obtained for the provinces located in first seismic zone of Turkey.

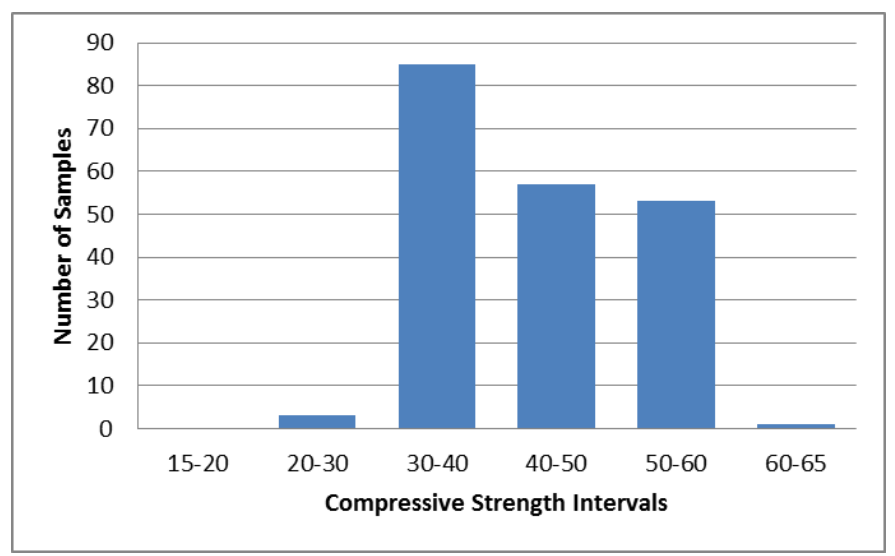

Fig 8 . The number of samples belonging to some intervals of compressive strength (MPa) for C20 in 2013

In Figure 8, the distribution of the test results of C20 concrete class is shown according to some compressive strength intervals. Considering a total of 597 samples belonging to $\mathrm{C} 20$ concrete class, 0 samples have a value smaller than $25 \mathrm{MPa}$; in other words, $100 \%$ of samples provide the value of $25 \mathrm{MPa}$ prescribed in TS 500-2000[8].

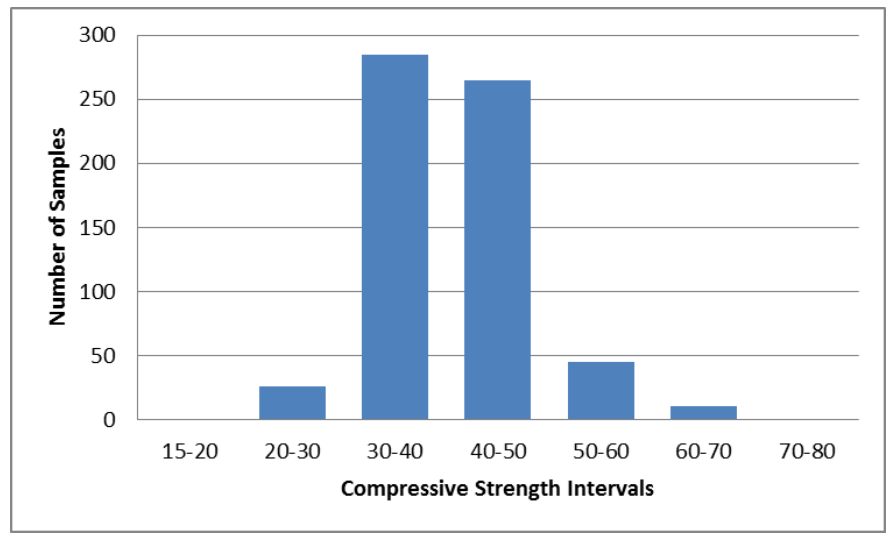

Fig 9. The number of samples belonging to some intervals of compressive strength (MPa) for C25 in 2013

In Figure 9, the distribution of the test results of $\mathrm{C} 25$ concrete class is shown according to some compressive strength intervals. Considering a total of 1902 samples belonging to $\mathrm{C} 25$ concrete class, 81 samples have a value smaller than $30 \mathrm{MPa}$; in other words, $4 \%$ of samples do not provide the value of $30 \mathrm{MPa}$ prescribed in TS 500-2000[8]. 


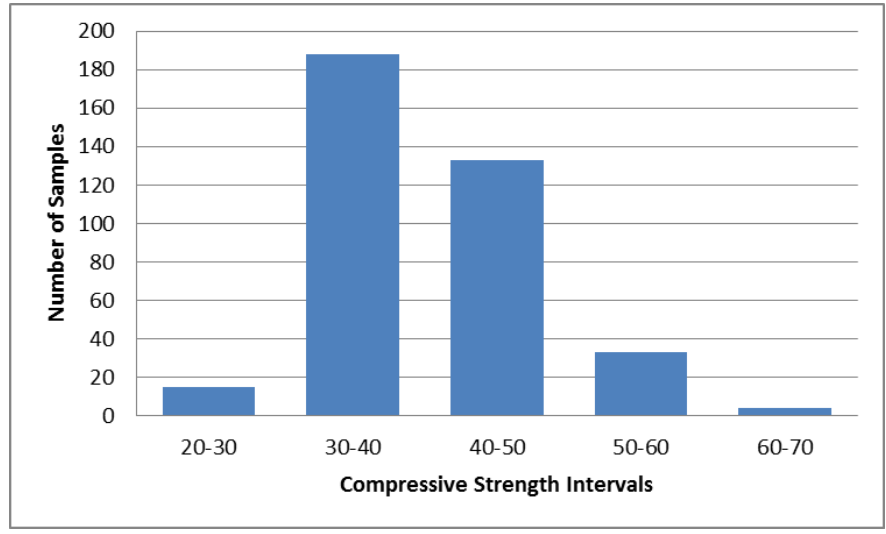

Figure 10. The number of samples belonging to some intervals of compressive strength $(\mathrm{MPa})$ for C30 in 2013

In Figure 10, the distribution of the test results of $\mathrm{C} 30$ concrete class is shown according to some compressive strength intervals. Figure 10 shows the certain number of the samples whose compressive strength is less than $37 \mathrm{MPa}$. Considering a total of 1119 samples belonging to C 30 concrete class, 384 samples have a value smaller than $37 \mathrm{MPa}$; in other words, $34 \%$ of samples do not provide the value of 37 MPa prescribed in TS 500-2000[8].

\section{RESULTS}

Based on the assessment of the concrete compressive strength test results of 14469 samples, the average value of the cube compressive strength is found to be around $35 \mathrm{MPa}$ for provinces located in the first seismic zone of Turkey. If this value is compared to the value obtained in the years of 19901995 (20.60 MPa), the mean concrete compressive strength is increased on the average of $\% 60$. This ratio points out that the high strength concrete is used in Turkey in comparison with the years before the two major earthquakes, namely the August 17 Kocaeli and the November 12 Düzce, in 1999.

$21 \%, 51 \%, 26 \%$ and $2 \%$ of the concrete produced in the provinces located in first seismic zone of Turkey belongs to C20, C25, C30 and C35 concrete classes between 2006 and 2012, respectively. On the other hand in 2013, 13\%, 52\%, $31 \%$ and $4 \%$ of the concrete produced in the provinces located in first seismic zone of Turkey belongs to C20, C25, C30 and C35 concrete classes, respectively When these ratios are compared with the ones obtained in the earlier years, it can be inferred that higher concrete classes has been used over the years.

In the stage of concrete production, not only the concrete class specified in the project must fulfill the minimum requirements given in specifications but also minimum variability on concrete compressive strength is targeted. In this study, it is seen that the variability of concrete compressive strength is considerably high; the weighted average cov is 0.21 for all concrete classes. For example, for C25 concrete class, the cube shaped compressive strength varies between a great range of $10 \mathrm{MPa}$ and $75 \mathrm{MPa}$.

Considering the concrete classes of C20, C25 and C30, the ratios of the samples of which compressive strength under the $25 \mathrm{MPa}, 30 \mathrm{MPa}$ and $37 \mathrm{MPa}$ (equivalent $150 \mathrm{~mm}$ cube compressive strengths in TS500-2000) are 14\%, $18 \%$ and $28 \%$, between 2006 and 2012 respectively. But in 2013, concrete classes of C20, C25 and C30, ratios of samples of which compressive strength under the $25 \mathrm{Mpa}, 30 \mathrm{Mpa}$ and $37 \mathrm{Mpa}$ are $0 \%, 4 \%$ and $34 \%$, respectively. In spite of the supervision and control on structures after devastating earthquakes occurred in Turkey, still these ratios are considerably high. These ratios point out that more attention should be paid the quality control on concrete.

\section{REFERENCES}

[1] Firat, F.K. and Yucemen M.S. (2008), Uncertainty Analysis for Reinforced Concrete Members Constructed in Turkey, International Conference on Construction and Building Technology, ICCBT, Kuala Lumpur, Malaysia.

[2] Erdoğan, T.Y. (2010). Concrete, METU Press, Ankara.

[3] TS EN 12390-3 (2010) Testing hardened concrete - Part 3 : Compressive strength of test specimens, Turkish Standards Institute, Ankara, Turkey.

[4] Ersoy, U. and Özcebe, G.(2004). Reinforced Concrete, Evrim Press, Ankara.

[5] TS EN 206-1 (2002) Concrete- Part 1: Specification, performance, production and conformity Turkish Standards Institute, Ankara, Turkey.

[6] ACI 318-08 (2008). Building Code Requirements for Concrete Structures and Commentary, American Concrete Institute, American Concrete Institute, Farmington Hills, MI, USA.

[7] Neville A. M. and Brooks J.J (2010). "Concrete Technology", Pearson Edu. Lim. Second Edition. England.

[8] TS 500, (2000). Requirements for Design and Construction of Reinforced Concrete Structures, Turkish Standards Institute, Ankara, Turkey.

[9] Akyuz, S. and Uyan, M. (1989). "A Study on Quality of Istanbul and the surrounding concrete", TMOB, $1^{\text {st }}$ National Concrete Congress, Istanbul.

[10] Firat, F.K. (2006). Statistical Evaluation of the Quality of Concrete Used in Turkey, Seventh International Congress on Advances in Civil Engineering, 11-13 October 2006, Yıldı Teknik University, Istanbul, Turkey.

[11] Firat, F.K., Sevim, O. and Sonmez, M. (2013), Investigation of Concrete Quality in Earthquake Regions after Devastating Earthquakes Occurred in Turkey," International Conference on Earthquake Engineering, 29 -31 May 2013, Skopje-Macedonia. 